\title{
UNA ESCENA ELECTORAL
}

\section{AN ELECTORAL STAGE}

\author{
Mariano Cicowiez \\ marianocicowiez@yahoo.com.ar \\ Facultad de Bellas Artes. Universidad Nacional de La Plata. Argentina
}

\begin{abstract}
The configuration of the still and in motion images of Cambiemos coalition, spread during the presidential election held in 2015 in Argentina, involved the arrangement of the bodies, objects and spaces as an equivalent to the speeches delivered by its candidates. The proposed study examines a set of pictures whose organization implied a cross reference operation towards the construction of what is real, subsidiary of the limitations revealed by the technological device.
\end{abstract}

\section{Keywords}

Election campaign; device; art

\section{Resumen}

La conformación de las imágenes fijas y en movimiento de Cambiemos, difundidas durante la contienda de elección ejecutiva celebrada en 2015 en la Argentina, comportó la disposición de cuerpos, objetos y espacios en calidad de equivalencia a los discursos pronunciados por sus candidatos. El estudio que se propone examina una serie de fotografías, cuya organización instituyó una operación de reenvíos hacia la construcción de lo real, subsidiaria de las limitaciones que revela el dispositivo tecnológico.

\section{Palabras clave}

Campaña electoral; dispositivo; arte 
La campaña de elección presidencial 2015 realizada en la Argentina por la alianza política Cambiemos estableció la conformación de sus imágenes fijas y en movimiento con carácter subsidiario de un orden instrumental acerca de los cuerpos, los objetos y los espacios (Verón, 1993) que integraron su composición. La instancia enunciativa que los convocó durante el período eleccionario instauró una escenificación de los encuentros ocurridos entre el, por entonces, candidato a la presidencia de la Nación, Mauricio Macri, y sus hipotéticos votantes, asumidos por la fuerza hoy gobernante en calidad de figurantes (Bourriaud, 2008) de sus productos de comunicación. A través del examen de las fotografías oficialmente difundidas por los órganos de prensa de Cambiemos, se advierte la intervención de los encuentros que involucraron a las sociedades política y civil, con objeto de reproducirlos en dispositivos tecnológicos como equivalencias de lo efectivamente acontecido.

Incluso con antelación al inicio formalmente establecido por la Dirección Nacional Electoral para divulgar producciones de carácter proselitista, las alianzas y los partidos políticos desplegaron una operatoria de distribución de fotografías a través, por ejemplo, del envío a diarios y a revistas de imágenes elaboradas por sus equipos de prensa, para que acompañasen los registros de las publicaciones gráficas de sus actos de propaganda. En este sentido, se han seleccionado tres fotografías que representan cuadros de síntesis de la especificidad del curso de la campaña.

\section{Escenario uno}

En la primera imagen se observa una escena inmediatamente reconocible: una situación de diálogo matizada con una ronda de mates, acontecida en un espacio privado, inmediato a un patio interno. Los objetos que determinan su composición visual (Barthes, 1986) se corresponden con el termo de agua, ubicado en el centro de la representación, y con las plantas y las macetas, en profundidad de campo, que connotan la disposición de la representación visual. El encuentro entre las esferas de las sociedades política y civil se recreó a través del acto compartido por Macri y por los ciudadanos que sujetan juntos, a la vez que exhiben, el mate en torno al que se reúnen sus cuerpos (Prensa Pro, 2015a) 
[Figura 1]. La fotografía capturó el instante esencial y operó como sinécdoque de un hecho que la excede y que ella misma construyó. En efecto, la parte por el todo que presenta la imagen no da cuenta, debido a sus limitaciones técnicas, de los espacios hacia los que se dirigen sus líneas de fuga, con seguridad correspondientes a la ubicación de los agentes y los asesores del candidato de Cambiemos. Si bien es cierto que «no hay nada menos real que un político embarrándose los mocasines rodeado de un séquito de treinta asesores y treinta periodistas» (Iglesias Illa, 2016, p. 55), también lo es, en este caso, que la ocultación manifiesta de marcas da cuenta del sujeto de la enunciación. La conversación desinteresada y presuntamente casual que compuso la gramática de producción de la fotografía se impone forzosamente, en carácter de noema barthesiano (Barthes, 2015), como testimonio de un encuentro que, no obstante, sí ha acontecido.

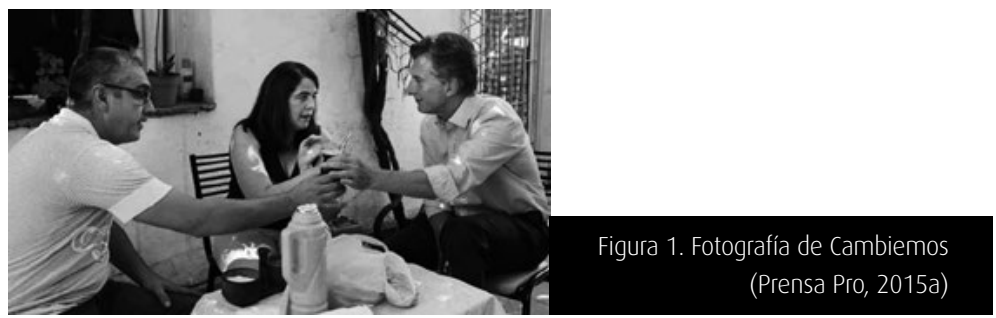

Los cuerpos, los objetos y los espacios que recrearon su disposición remiten a la construcción de una serie de ejes que organizaron el pulso de la campaña de Cambiemos y que se observaron en distintos soportes de comunicación. La empatía, la comprensión, la cercanía y el encuentro sustancial entre el candidato y los hipotéticos adherentes fueron los rasgos temáticos que atravesaron la contienda electoral. Por lo tanto, la función de sustitución de la visita de Macri, que se efectuó a través del registro y de la puesta en circulación de una imagen de campaña, resulta insubsistente toda vez que el signo no reemplaza a su objeto sino que lo alude en una circunstancia o en una condición (Magariños de Moretín, 2002).

\section{Escenario dos}

La ensayista y novelista estadounidense Susan Sontag (2005) asegura que «todo estilo comporta una decisión epistemológica[...] las decisiones estilísticas, al centrar nuestra atención en determinadas cosas, suponen también un estrechamiento de nuestra atención, una negativa a permitirnos ver otras» 
(pp. 65-66). Al respecto, la segunda fotografía presenta un cuadro de situación de carácter similar a la imagen precedente. Los cuerpos de Macri y de los ciudadanos se ubican sobre los márgenes del encuadre, en relación con un objeto que nuevamente connota un estilo de composición que se presume accidental. La mujer que luce una prenda de vestir azul ensaya líneas de fuga que nos permiten conjeturar que su sonrisa se dirige hacia personas ubicadas fuera de campo, a la vez que los palos de madera que sujeta operan como materia significante del conjunto de la organización de la fotografía (Prensa Pro, 2015b) [Figura 2]. La acción que destaca esta imagen se corresponde con un encuentro fortuito en un espacio público entre el candidato y los ciudadanos, sorprendidos cuando barrían la vereda o caminaban por allí. No obstante, la ubicación centrada del extremo de uno de los elementos de limpieza permite asumir que se trata de una selección cuidada de cuerpos, de objetos y de espacios, concluyentes en la estructura del proyecto.

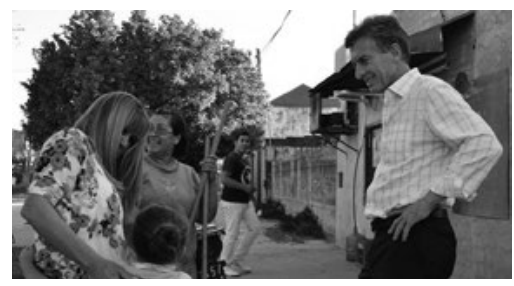

Conforme con el mate, los palos de madera - tanto si pertenecen a escobas, a secadores 0 a cepillos - remiten a situaciones reconocibles por parte del espectador. Se trata de objetos que reenvían a la vecindad, al esfuerzo y al trabajo que demanda el cuidado del espacio público de tránsito y de conversación. En este contexto se ubicó el cuerpo de Macri, solícito a prestar su colaboración y dispuesto a intervenir en la renovación de las consuetudinarias prácticas partidarias argentinas.

El vínculo que la imagen estableció con la realidad es nuevamente artificioso. A la veracidad histórica que ostenta la fotografía acerca de este encuentro entre política y sociedad civil, se opone la veracidad perceptiva que la limita y que redefine su estatuto (Gubern, 1974). Una vez más, el diseño de la imagen precisó menos acerca de las características visuales del suceso que de una interpretación concertada a los intereses promocionales de los equipos de comunicación de Cambiemos.

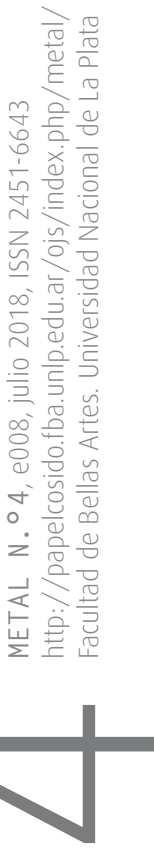




\section{Escenario tres}

Daniel Belinche y Mariel ciafardo (2008) aseveran, con relación al estereotipo, que se trata de una figura que «se reitera y se reproduce sin mayores transformaciones. Se caracteriza por ser un cliché, un lugar común, un esquema fijo que no requiere una participación activa del intérprete sino, por el contrario, apenas demanda su reconocimiento inmediato» (p. 28). En la tercera fotografía se reitera, en orden estereotipado, la presencia del cuerpo de la mujer que viste una prenda de matiz floreada, el gesto de atención dispuesta hacia los residentes, proferido por Macri, y un objeto que asegura la connotación de la escena acontecida en un barrio urbano. En este caso, la puerta enrejada y la plancha de metal que recubre su zona inferior configuran la materia significante de la organización integral de la representación (Prensa Pro, 2015c) [Figura 3]. Los objetos mencionados reenvían al temor, al resguardo y a la desconfianza que conducen la vida en el espacio público seleccionado, a la vez que asoman en calidad de índices que procuran rectificar las disposiciones técnicas del dispositivo fotográfico. En este sentido, la imposibilidad del registro de las voces se atenuó con la configuración de una puesta en escena que ubicó en su centro información determinante.

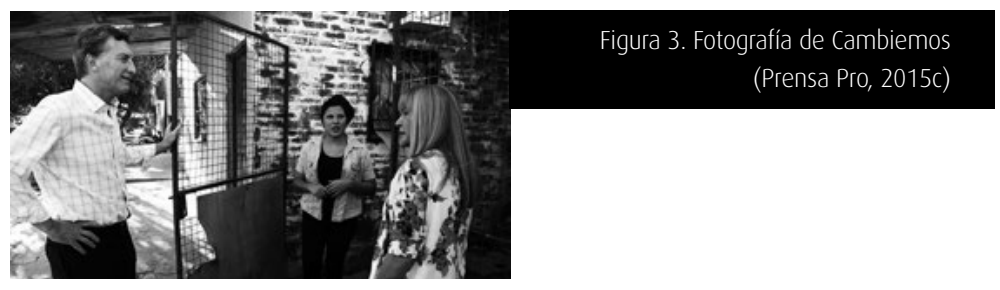

\section{Consideraciones}

Las imágenes fijas de Cambiemos difundidas en 2015 con motivo de la celebración de las Primarias Abiertas Simultáneas y Obligatorias (9 de agosto), de la primera vuelta electoral (25 de octubre) y del ballottoge (22 de noviembre) constituyeron un cuerpo de observación para examinar el proceso de mediatización que predomina en una sociedad de consumo industrial avanzada. Al respecto, Eliseo Verón (2001) asegura:

[una] sociedad industrial mediática hace estallar la frontera entre lo real de la sociedad y sus representaciones. Y lo que se comienza a sospechar es que los medios no son solamente dispositivos de reproducción de un «real» al que copian más o menos correctamente, sino más bien dispositivos de producción de sentido (pp. 14-15). 
La reproducción seriada de eventos de campaña que involucran a las sociedades política y civil, expositiva de un modelo que concierne menores modificaciones en la composición de su estructura y de su fuerza narrativa, permitió exponer regularidades acerca de la presunción de la fotografía, en este caso electoral, como dispositivo técnico que captura lo real en cualquiera de sus manifestaciones. La vanidad de los objetivos estipulados por los equipos de comunicación de cambiemos no alcanzó, sin embargo, para establecer una asociación no mediada y, por tanto, construida, cuya circulación en diversas plataformas añadió una nueva instancia de producción de sentido.

Los cuerpos de Macri y de los ciudadanos, reconvenidos en vecinos, los objetos de uso doméstico y de resguardo de una vivienda particular, y los espacios de orden público y privado, han sido, de modo respectivo, trabajados, seleccionados y dispuestos para intervenir como material significante. Asimismo, constituyen ejemplos acerca del tratamiento que el dispositivo tecnológico instituye, en relación con la información que compone la diégesis de las imágenes de uso electoral.

De este modo, si no está en duda el noema barthesiano de la fotografía, sí lo está el procedimiento que lo originó y las condiciones técnicas de su registro. Con respecto a la primera relación, no cabe conjeturar que los acercamientos entre Macri y los ciudadanos se corresponden con encuentros casualmente sucedidos. Y de manera subsidiaria, la segunda relación asegura una construcción mediatizada que comprende una planificación integral de los productos de campaña. No es un hecho menor, sino, por el contrario, ciertamente nodal a la comunicación de Cambiemos, que el diseño de la composición de las imágenes preservase una serie de unidades mínimas de carácter temático, retórico y enunciativo en el conjunto de su producción visual y audiovisual. Las figuras de un candidato que poco habla y en mayor medida escucha, los objetos que connotan cercanía, inmediatez, confianza y contigüidad, y los espacios habituales como un patio interno o el frente de una vivienda, en los cuales se escenifica la representación, han sido utilizados en un número de imágenes que excede abiertamente el cuerpo fijado para realizar esta exposición.

En definitiva, la fotografía, en este caso conducida al servicio de una planificación de alcance nacional, alude a un aspecto o a una circunstancia de los acontecimientos que definen su información. El carácter instrumental del dispositivo opera sobre una selección del universo referencial que replica la estructura iterativa reconocida, la cual forma sistema con un esquema narrativo que concibe, entre el candidato y los electores, una disposición confederada. El mate, las escobas y los enrejados recuperan una asociación de continuidad, un denominador de lectura relacional acerca de las imágenes de Cambiemos 2015. 


\section{Referencias}

Barthes, R. (1986). Lo obvio y lo obtuso. Imógenes, gestos, voces. Barcelona, España: Paidós.

Barthes, R. (2015). La cámara lúcida. Noto sobre la fotografía. Buenos Aires, Argentina: Paidós.

Belinche, D. y Ciafardo, M. (2008). Los estereotipos en el arte. Un problema de la educación artística. Los artistas son de Piscis. Lo Puerto. Publicación de arte y diseño, 3(3), 27-38.

Bourriaud, N. (2008). Estética relacional. Buenos Aires, Argentina: Adriana Hidalgo.

Gubern, R. (1974). Mensajes icónicos en la cultura de masas. Barcelona, España: Lumen.

Iglesias Illa, H. (2016). Combiomos. Mauricio Mocri presidente. Día a día, la campaña por dentro. Buenos Aires, Argentina: Sudamericana.

Magariños de Moretín, J. (2002). Charles Sanders Peirce: sus aportes a la problemática actual de la semiótica [Apunte de Cátedra]. Semiótica, Facultad de Periodismo y Comunicación Social, Universidad Nacional de La Plata, La Plata, Argentina.

Prensa Pro (2015a). Sin título [Fotografía]. Recuperado de http://diaadia. viapais.com.ar/cordoba/en-campana-sofia-gatica-invito-macri-su-casa

Prensa Pro (2015b). Sin título [Fotografía]. Recuperado de https://www.infobae.com/2015/04/25/1724605-en-chaco-macri-prometio-aprovecharlos-recursos-sacar-la-gente-la-pobreza/

Prensa Pro (2015c). Sin título [Fotografía]. Recuperado de:https://www. infobae.com/2015/04/25/1724605-en-chaco-macri-prometio-aprovecharlos-recursos-sacar-la-gente-la-pobreza/

Sontag, S. (2005). Contra la interpretación. Buenos Aires, Argentina: Alfaguara. Verón, E. (1993). La semiosis social. Fragmentos de una teoría de la discursividad. Barcelona, España: Gedisa.

Verón, E. (2001). El living y sus dobles. Arquitecturas de la pantalla chica. En El cuerpo de los imágenes (pp. 13-40). Bogotá, Colombia: Norma. 